\title{
Learning in primary health care settings: Australian undergraduate nursing students' perspectives
}

\author{
Lisa McKenna ${ }^{1}$, Arlene Parry ${ }^{1}$, Catherine Kirby ${ }^{2}$, Kara Gilbert ${ }^{2}$, Rose Griffiths ${ }^{3}$ \\ 1. School of Nursing and Midwifery, Monash University, Victoria, Australia. 2. Office of the Pro Vice-Chancellor (Berwick \\ and Peninsula), Monash University, Victoria, Australia. 3. South Eastern Health Providers Association, Dandenong, Victoria, \\ Australia.
}

Correspondence: Lisa McKenna. Address: School of Nursing and Midwifery, Monash University, Clayton, 3168, Victoria, Australia. Email: lisa.mckenna@monash.edu

Received: J une 16, 2014

Accepted: August 27, 2014

Online Published: September 5, 2014

DOI : $10.5430 /$ jnep.v4n12p1

URL: http://dx.doi.org/10.5430/jnep.v4n12p1

\begin{abstract}
Objective: Primary based health care is increasing. While student clinical placements in primary health care are not new, little is known about what students can learn and there is little evidence around the value they add to overall clinical learning. This study explored undergraduate nursing students' experiences of learning in two primary health care settings: general practice and Royal District Nursing Service.

Design: A qualitative design using semi-structured interviews and focus groups was chosen. Data were analysed thematically.

Methods: Nine undergraduate students undertook voluntary one-week placements in each of general practice and district nursing. Following completion of placements, students were interviewed about their placement experiences and focus groups were undertaken with the nurses involved in the study from both the GP setting and District Nursing setting.

Results: Three key themes emerged: broadened perspectives, where students' initial perceptions of primary health nursing were challenged; skills development, with students receiving opportunities to consolidate previously learned skills alongside new skills to be acquired; and contexts of care, enabling students to see the bigger picture of health care delivery, beyond what is delivered in acute settings.

Conclusions: Nursing students need to be exposed to expanded settings of care in order to fully appreciate autonomous primary health care nursing roles and gain understandings of how this links to care in the acute care setting. Primary health care based placements are also a vital component in workforce planning exposing careers in this setting as sustainable, viable and highly rewarding.
\end{abstract}

\section{Key words}

Clinical placement, General practice, Nurse education, Primary health care

\section{I ntroduction}

Over recent years, changes to inpatient care have resulted in shortened lengths of hospital stay and a higher patient turnover, with subsequent care being provided in the primary health care setting such as the patients' own home. In 
Australia, changing models of health care, and in particular, chronic disease management, have seen nurses play increasingly central roles in the delivery of primary health care. Primary health care is delivered in multiple ways, but primarily through district nursing and nursing in general practice. Given these changes, it is therefore essential to consider the contribution of clinical placements in the primary health care settings to students' learning, especially as undergraduate courses are designed to produce generalist nurses who can practice in many different contexts.

\section{Background}

Nursing in the primary health care setting is diverse and takes many forms in Australia such as district nursing, general practice nursing and school nursing. District nurses provide home-based care, inclusive of complex chronic disease management, the demand for which is growing in response to earlier hospital discharge and the increasing ageing population ${ }^{[1]}$. District nursing has had a long history in Australia, beginning in the city of Melbourne in 1885, and developing in other cities over subsequent decades ${ }^{[2]}$. As a result of government policies, district nursing experienced significant growth in the 1970s and 1980s ${ }^{[2]}$.

In comparison, nursing in general practice is a relatively new and rapidly growing clinical specialty in Australia ${ }^{[3,4]}$. The numbers of practice nurses working in Australia has reportedly increased from 3,255 in 2003-2004 to 10,759 in 2010$2011^{[5]}$. Subsequently, the numbers of general practices employing nurses is gradually increasing with $63.3 \%$ reporting the employment of nurses in $2012^{[6]}$. The general practice nurse's role is extremely diverse and varies from practice to practice, as does their level of autonomy and responsibility, with almost half of these nurses practising at the level of advanced specialist ${ }^{[7]}$.

The general practice setting has traditionally provided a learning environment for medical education rather than nursing education, but research with medical students highlights the valuable role that practice nurses have as educator ${ }^{[8]}$. Smith $e t$ al. ${ }^{[8]}$ explored medical students' learning from practice nurses, finding that the nurses were more likely to question and challenge the students, as opposed to the GPs taking this responsibility. In concluding, the authors recognised that practice nurses had the potential to play an important role in such education. However, with an ageing nursing workforce in Australian general practice, Halcomb et al. ${ }^{[9]}$ argue that it is also important that nursing students also have opportunities to undertake clinical education in the general practice setting.

With the dynamic nature of nursing, curricula need to be continually responsive to contemporary nursing practice. Parker et al. ${ }^{[7]}$ assert that undergraduate nursing curricula should seek to better address primary care nursing in order to prepare students for practice in such contexts. Primary health care involves the delivery of individualised care as well as preventative health and health promotion; hence primary health care placements offer unique and important additional aspects to student learning. Jackson and Saltman ${ }^{[10]}$ contend that student exposure to such settings offers access to various care delivery models along with gaining insight into interprofessional health care. Primary health nursing requires a different skills set than those used in acute environments, such as looking beyond individual patient conditions and their management to more broad, population-based perspectives ${ }^{[11]}$. Of particular importance, primary health care placements offer students exposure to the full continuum of nursing care ${ }^{[12]}$ that cannot be appreciated through acute placements only. There is also great variety between primary health care settings, which then simultaneously differ in the types of learning opportunities they offer to students ${ }^{[13]}$. This further suggests that undergraduate nursing students should have exposure to a variety of primary health care settings during their courses. While some universities have sought to expose students to general practice settings, Parker et al. ${ }^{[7]}$ highlighted that nursing students attending such placements were at times not aware of what primary care meant and suggested that students need to be better prepared for commencement in such placements. This further reinforces the need for curricula to prepare students adequately for primary care experiences.

Little research has been undertaken to examine the conduct and learning experiences of nursing student placements in primary health care settings. In one study, Halcomb, Peters and McInnes ${ }^{[14]}$ explored general practice nurses' perspectives and experiences of mentoring nursing students in Australian general practice clinics. Participating nurses perceived 
hosting students as a way of promoting practice nursing as a future career option. In addition, students were able to undertake clinical skills that they had previously been unable to practise in acute settings. While this provides some evidence around what nursing students can do in primary health care based placements, no literature could be sourced that examined students' perspectives on such learning experiences.

\section{Methods}

This study sought to examine nursing students' perspectives and learning from clinical placements in two primary health care based nursing models: district nursing and general practice. Following ethical approval from the relevant university ethics committee and approval from the selected clinical partners, students undertaking their second year of a Bachelor of Nursing at an Australian university were invited to participate in a voluntary placement program, spending one week (5 days) in the District Nursing setting and one week (5 days) in the General Practice setting in a metropolitan area. An evaluation was undertaken to explore student and preceptor experiences of the placements, the benefits and difficulties associated with nursing placements in these settings, and strategies to address these. This mixed methods research was undertaken to trial a placement program, and evaluate it utilising focus groups and one-on-one interviews following completion of the trial. Verbal and survey-based feedback was also sought from preceptors who participated in the preceptor training workshops, however this paper reports the findings from the students' perspectives. In collaboration with clinical placement providers, 5 GP practices and 3 district nursing centres were selected as the placement venues for the study. General practice placements were sought within clinics that employed a practice nurse and would provide students with insight into the multidisciplinary aspects of chronic care management and promote positive practice experiences.

District nursing placements were selected based on their proximity to the university and students and the availability of nurses who could provide preceptorship within their current workloads. Nine students participated in the study; all of whom were completing the second year of their degree. All participating students were female, with an age range of 19 to 52 years and mean age of 27.4 years. All participants were residing in metropolitan Melbourne. The placements occurred during a non-teaching period at the end of Semester 2, after regular student examinations were complete. This timing was selected to minimise the impact on students' regular course commitments and to avoid any undue stress. During each placement, the student was practising under one-on-one supervision with a member of staff who had completed supervisory training (preceptor training).

Half of the participating students were hosted by the selected general practices during the first week with students undertaking one orientation/education day followed by four days on-site at their placement clinic. This involved both observational and hands-on experience for students under direct supervision of the clinic nurse and other staff where possible such as the GP or Mental Health specialist nurse. The other half of the students undertook a district nursing placement in the first week, which involved going on the road with their supervising nurse to observe nursing care provided in home settings, and assist the nurse as appropriate. Students then swapped their placements for the second week.

Following the placement trial, students were asked to participate in a one-hour focus group in order to gain information about their perceptions and experiences of the placements. There were 5 students in attendance at the focus group, with an additional four one-on-one telephone interviews conducted with students who were unable to participate in the focus group. A schedule of open-ended questions was used to guide discussions; however the facilitator was also guided to some extent by participants' discussions, in order to identify salient issues. All interviews lasted less than one hour in length. Data were analysed using thematic analysis informed by the work of Braun and Clarke ${ }^{[15]}$. Transcripts were read multiple times by individual members of the research team to promote familiarisation with the data and identify general trends. Data were then coded and later collated into themes. Themes were subsequently reviewed and named. Finally, members of the research team met to validate individual findings and determine final themes. 


\section{Results}

From the analysis of student interviews, three main themes emerged: Broadened Perspectives, Skills Development and Appreciating Contexts of Care.

\subsection{Broadened perspectives}

Students expressed that a number of their perspectives about community-based nursing had been expanded through their clinical experiences. In particular, many were surprised at how their initial perceptions of the nature of community nursing were challenged, with some students commenting that they did not even know that nurses worked in general practice.

I wasn't necessarily expecting to enjoy GP [general practice] as much as I did. I think I was expecting it to be a bit mundane kind of sitting in a GP surgery. I never really considered it as an option. [IV 3]

I didn't know I was getting a lot of immunisations and things. I wasn't sure what the nurses would do in a general practice clinic because I have never seen one myself. [IV 2]

I've never been in a GP clinic where there was a practice nurse...I didn't know nurses could work in a GP clinic. [FG]

Having only seen nurses practising in acute hospital settings, students were particularly surprised at the broad scope of practice and levels of autonomy of nurses with whom they worked, particularly that some clients attended the clinic just to see the nurse.

She [Practice Nurse] has her own patients and they would come in just to see her and not come in to see the doctors and it was...good to see that bit of autonomy. [IV 3]

We did a fair few [health assessments in GP]. We went to a nursing home one afternoon and did one on someone there as well. Then we saw a few residents at a nursing home. [IV 2]

I thought I would be there doing paperwork...I didn’t really think that I would be following the nurse around and a nurse in general practice, she has more scope than a nurse in a hospital setting. She has to be independent...an advocate for her patient to the GPs...it was beyond what I expected. [FG]

However, during the focus group the level of autonomy afforded to practice nurses involved in this program emerged as varying considerably across general practices:

Our nurses were more just doing the jobs the doctors didn't want to do themselves. I found that they [GPs] were like "can you just measure this person, how tall they are and can you clean up the mess I have made". [IV 4]

The experience in the primary health care settings opened students' eyes with regard to potential career pathways that they had not previously considered. However, most felt that it was not something they would do early in their careers as registered nurses, instead preferring to gain experience in an acute setting first. For one student, the placements provided the realisation that this setting as a future career was not an option.

That exposure to different things that you can do was just fantastic to actually be able to see there are so many options out there. [IV 3]

It’s an appealing career option, but not necessarily straightaway...something down the track. [FG]

I didn't know that it was going to be fun. I just thought maybe I could do this in the future. [FG] 
It's something I could see doing when I'm older with kids because I really like the idea of it being nine to five and you don't have to do that much on the weekend either. [IV 4]

\subsection{Skills development}

One area that students found particularly beneficial was the opportunity to consolidate and further extend upon previously learned skills, such as basic nursing care, wound care and medication administration, accompanied by opportunities for new skills to be acquired. This included the opportunity to improve the students' knowledge of the Medicare system and how to perform advanced health assessments.

You saw a lot of wounds...I found at uni you've been taught a few techniques and things like that but we hadn't been taught what sort of dressings suit which types of wounds. ...I found that really interesting [IV 4]

I pretty much did everything but compression bandaging because I didn’t really know much about that. [IV 4]

We'd do medications.... and showering, the wound dressings so I was able to do most of those things. With the general practice, I did the injections, I immunised the babies. [IV 2]

Skills consolidation was accompanied by opportunities for new skills to be acquired.

I got the chance to prepare the treatment room for the doctor to do minor surgeries like biopsy. [IV 1]

I did a lot of assessments to begin with because it was a new clinic they had a lot of new patients coming in so I did all the basics like height, weight stuff. [FG]

\subsection{Appreciating contexts of care}

The primary health care placements afforded students opportunities to see the bigger picture of health care delivery, beyond what is delivered in the acute setting and mostly what is experienced through their regular clinical placements.

It was interesting to see how it all worked and fit together. [IV 4]

I did learn a lot about Medicare and stuff that didn’t know before. [FG]

When they were doing the care plan they don't have the patient on site. They do the care plan and then send it to the doctor to check and if he's happy with it that's when they send it to Medicare. [IV 1]

Unlike other settings they had been in, students were able to see nurses playing a central role in preventative health care.

I found that there were a lot more preventative health issues particularly in the GP...it was a lot more focused on preventing health issues rather than, okay they're in hospital, we're going to treat them. [FG]

The placements contributed to students' understanding of the continuum of care and how other health professionals were part of a team holistically caring for an individual. Unlike in acute settings, they were able to directly witness how other professionals collaborated and contributed to the individual's care.

It gave me good insight as to how they [health professionals] all work together, how to achieve better health for an individual person... where it starts and how it progresses and that was interesting. In the acute and emergency setting it is like a snap shot and this was following them throughout. [IV 4]

Through the general practice clinical when we were planning the care plan, it really helped because it was the nurse's role to do a plan of what we want the patient to do, like refer them to the ophthalmologist, podiatrist, get 
regular checks with the GP...that really helped us to see everything lines up and gives the patient holistic care. [FG]

It’s also good with district nursing to see how nurses work as a team. [FG]

Providing care in patients' homes, rather than acute care settings, presented students with new challenges. Some students commented on differences in district nurses' relationships with their clients, and variations in reactions to them.

I had a couple of people who didn't want care and then suddenly you're going into their home and they just don't want you there. I found it more confronting that they're not coming to you. You are actually going into their house and some of them just didn't want you there. A lot of people are totally non-compliant, especially in diabetes which...is really frustrating. [FG]

Most of my clients were very compliant with what they were doing and they were happy to have the nurse there. These patients you saw pretty much every day so they knew who you were, they were expecting the nurse and if you were running five minutes late they would get a call, why aren’t you here? [FG]

Not a lot of people talk about community nursing and I found it really, really nice because you go to see the patients in their environment, independent, whereas in a hospital they are really reliant on you. [FG]

They can do everything from home. We went in and put up IVs for people and then just sat around for a while, had a chat, waiting for it to run. I was really surprised and I think it's great...if you can go home and have the nurse come home and put up the IV, you're with your family in your own space. [FG]

One of the most notable aspects of student learning was around how primary health care nurses managed clients who did not speak English. Students had previously been in acute hospital settings where interpreters were available when patients did not speak English. Students commented on how the nurses, in both types of placement, dealt with such patients without the aid of interpreters.

You are going into different peoples' homes and in some of them communication was very hard and trying to educate this person. [IV 3]

... my preceptor told me to do a health assessment on a lady who was over 75 but English was her second language which wasn't really strong. I tried to do as much as I could but... our understanding could only get so far. When I called my preceptor she got so much further because of her experience...It was very interesting to see her communicating and getting the information out...A lot of hand gestures, just inferring information. [FG]

\section{Discussion}

Primary health care nursing is a rapidly growing area due to earlier hospital discharges, an increasing aging population and an increasing number of individuals across the lifespan living with chronic disease. As a result of this, nurses in primary practice provide care for many complex and chronic health conditions ${ }^{[1,16]}$. Furthermore, Halcomb et al. ${ }^{[9]}$ argue that within Australian general practice there is an ageing, experienced workforce, and the subsequent need to recruit nurses into the area is vitally important. Clinical placements in the general practice setting provide practice nurses with opportunities to promote their roles as a potential career option ${ }^{[17]}$. Albutt, Ali and Watson ${ }^{[18]}$ identified through interviews with nurse educators that undergraduate nursing students were not prepared for placements in these settings and were therefore not confident working in the primary care sector on completion of their degrees.

Importantly, clinical placements in these settings have the potential to offer different and varied types of learning experiences for nursing students than traditional, acute hospital placements. They also expose students to possibilities for 
future career pathways ${ }^{[7,17]}$. Participants of this study articulated that without such clinical experience, they would have little understanding of the range of career possibilities available to them. Some even expressed not being aware that nurses played a role in general practices, while others were surprised at the level of autonomy of nurses in both district nursing and general practice. Given that universities seek to educate generalist nurses who are equipped to practise in diverse types of roles, it appears imperative that courses offer all undergraduate nursing students opportunities to undertake placements in the community/primary health care setting ${ }^{[18,19]}$.

Worth noting from this study was the view that the students involved recognised that nurses working in primary care settings were more resourceful, and provided care that was more holistic, than what they had expected. They inferred that in acute settings, aspects of care were often referred on to other health professionals with no subsequent follow-up. Students discussed how primary health care nurses communicated with non-English speaking clients without dependence on interpreters, and how different members of the interprofessional team worked together on an individual's care. This reinforces the assertions of Seib et al. ${ }^{[12]}$ that primary health care placements provide opportunities for students to experience the full continuum of care, and Jackson and Saltman ${ }^{[10]}$ that students can experience interprofessional health care. Furthermore, it was only through these placements that students were able to see nurses involved in preventative health care and health education activities for the management of chronic conditions ${ }^{[11]}$. Our study also found that students had opportunities to consolidate previously learned skills and had exposure to other skills not seen in acute settings, such as immunisation, care planning and other screening programs.

The findings of this study do need to be considered cautiously as they cannot be generalised across populations, however, the findings do add to the body of knowledge around nursing students' learning in primary health care based clinical settings. It is important to acknowledge the limitations to this research that impede conclusions that may be drawn. The sample of students and preceptors was small; a reflection of the time and resource intensive nature of participation in this research. The student sample was drawn from one university in Australia with nursing students who volunteered for an additional clinical placement, hence were likely to have been particularly motivated individuals. Notable, initial interest was very high among nursing students, however many were unable to participate due to clashes with compulsory placements, work and family commitments. In addition, the clinical settings hosting the students for this study were carefully selected as they were considered to be supportive to students and as a result were invited to participate, however only one student could be accommodated per site. This then impacted on the student sample size selected. In fact, there is much ground to cover in making nursing placements in GP settings attractive to GPs and GP practices, especially while clinical placement remuneration applies to medical students but not nursing students. This may have impact on the learning experiences and opportunities for nursing students in general practice. Hence, student experiences in other settings may be different, and larger studies are warranted to further examine student learning and outcomes from community placements.

\section{Conclusion}

Undergraduate nursing education seeks to educate generalist nurses who can practise effectively in a range of health care settings. Increasingly, care is being delivered in the community. Clinical placements in primary health care settings are necessary to expose students to the diversity that nursing in this field can offer along with developing the necessary knowledge and skills to practice in these settings. Placements in general practice and in district nursing offer valuable learning opportunities not accessible or available in acute settings, along with highlighting the important role primary health care nurses play in the provision of holistic healthcare. Furthermore, such exposure will assist in attracting nurses into primary care practice and help to address future workforce recruitment needs. Without exposure to primary care practice settings, students may not develop awareness of, and appreciation for, autonomous nursing roles and the potential nursing careers available to them. This is important to encourage ongoing recruitment into the expanding primary health care nursing workforce. 


\section{References}

[1] Wilkes L, Cioffi J, Warne B, Harrison K, Vonu-Boriceanu O. Clients with chronic and complex conditions: Their experiences of community nursing services. J Clin Nurs. 2007; 17: 160-168. PMid:18578792

http://dx.doi.org/10.1111/j.1365-2702.2008.02454.x

[2] Madsen,W. Bottom lines: The influence of government funding on the 20th century district nursing practice in Australia. J Clin Nurs. 2009; 18: 2710-2716. PMid:19744022 http://dx.doi.org/10.1111/j.1365-2702.2009.02903.x

[3] Hoare KJ, Mills J, Francis K. The role of Government policy in supporting nurse-led care in general practice in the United Kingdom, New Zealand and Australia: An adapted realist review. J Adv Nurs. 2012; 68: 963-980. PMid:22070658 http://dx.doi.org/10.1111/j.1365-2648.2011.05870.x

[4] Porritt J. Policy development to support nursing in Australian general practice: An overview. Contemp Nurs. 2007; 26 : 56-64. http://dx.doi.org/10.5172/conu.2007.26.1.56

[5] Primary Health Care Research and Information Service. PHCRIS Fast Fact Practice nurse numbers in Australia, 2003-04 to 2010-11. 2014; http://www.phcris.org.au/fastfacts/fact.php?id=4824. Accessed 13 June 2014.

[6] Australian Medicare Local Alliance. General Practice Nurse National Survey Report 2012. Australian Medicare Local Alliance, Canberra: 2012.

[7] Parker R, Walker L, Hegarty K. Primary care nursing workforce in Australia. Aust Fam Physician. 2010; 39: 159-160. PMid:20369120

[8] Smith P, Cotton P, O'Neill A. 'Can you take a student this morning?' Maximising effective teaching by practice nurses. Med Educ. 2009; 43: 426-433. PMid:19422489 http://dx.doi.org/10.1111/j.1365-2923.2009.03308.x

[9] Halcomb EJ, Davidson PM, Salamonson Y, Ollerton R, Griffiths R. Nurses in Australian general practice: Implications for chronic disease management. J Clin Nurs. 2008; 17: 6-15. PMid:18298752 http://dx.doi.org/10.1111/j.1365-2702.2007.02141.x

[10] Jackson D, Saltman DC. Preparing health professionals for community-based practice: Some issues for consideration. Contemp Nurs. 2011; 38: 201-203. PMid:21994987

[11] Wade GH, Hayes E. Challenges and opportunities associated with preceptored community health clinical experiences. Public Health Nurs. 2010; 27: 459-467. PMid:20840716 http://dx.doi.org/10.1111/j.1525-1446.2010.00879.x

[12] Seib C, English R, Barnard A. Teaching undergraduate students community nursing: Using action research to increase engagement and learning. J Nurs Educ. 2011; 50: 536-539. PMid:21627051 http://dx.doi.org/10.3928/01484834-20110531-03

[13] Baglin MR, Rugg S. Student nurses' experiences of community-based practice placement learning: A qualitative exploration. Nurs Educ Pract. 2010; 10: 144-152. PMid:19570716 http://dx.doi.org/10.1016/j.nepr.2009.05.008

[14] Halcomb EJ, Peters K, McInnes S. Practice nurses experiences of mentoring undergraduate nursing students in Australian general practice. Nurs Educ Today. 2012; 32: 524-528. PMid:21908081 http://dx.doi.org/10.1016/j.nedt.2011.08.012

[15] Braun V, Clarke V. Using thematic analysis in psychology. Qual Res Psychol. 2006; 3: 77-101. http://dx.doi.org/10.1191/1478088706qp063oa

[16] Keleher H, Parker R. Health promotion by primary care nurses in Australian general practice. Collegian. 2013; 20 : $215-221$. http://dx.doi.org/10.1016/j.colegn.2012.09.001

[17] Peters K, Halcomb EJ, McInnes S. Clinical placements in general practice: Relationships between practice nurses and tertiary institutions. Nurs Educ Pract. 2013; 13: 186-191. PMid:23069694 http://dx.doi.org/10.1016/j.nepr.2012.09.007

[18] Albutt G, Ali P, Watson R. Preparing nurses to work in primary care: Educators' perspectives. Nurs Stand. 2013; 27: 41-46. PMid:23821989 http://dx.doi.org/10.7748/ns2013.05.27.36.41.e7085

[19] Henderson J, Koehne K, Verrall C, Gebbie K, Fuller J. How is primary health care conceptualised in nursing in Australia? Health Soc Care. 2014; 22: 337-351. PMid:23952616 http://dx.doi.org/10.1111/hsc.12064 